Accepted for publication in the Journal of Applied Physics.

\title{
Mixed Metal Films With Switchable Optical Properties
}

\author{
T. J. Richardson ${ }^{(a)}$, J. L. Slack, B. Farangis, and M. D. Rubin \\ Building Technologies Department \\ Environmental Energy Technologies Division \\ Ernest Orlando Lawrence Berkeley National Laboratory \\ University of California \\ 1 Cyclotron Road \\ Berkeley, California 94720
}

October 2001

This work was supported by the Assistant Secretary for Energy Efficiency and Renewable Energy, Office of Building Technology, State and Community Programs, Office of Building Research and Standards of the U.S. Department of Energy under Contract No. DE-AC03-76SF00098. 


\title{
Mixed Metal Films With Switchable Optical Properties
}

\author{
T. J. Richardson, J. L. Slack, B. Farangis, and M. D. Rubin \\ Building Technologies Department, Environmental Energy Technologies Division, \\ Lawrence Berkeley National Laboratory, Berkeley, California 94720
}

\begin{abstract}
Thin, Pd-capped metallic films containing magnesium and first row transition metals ( $\mathrm{Mn}, \mathrm{Fe}, \mathrm{Co})$ switch reversibly from their initial reflecting state to visually transparent states when exposed to gaseous hydrogen or following cathodic polarization in an alkaline electrolyte. Reversion to the reflecting state is achieved by exposure to air or by anodic polarization. The films were prepared by co-sputtering from one magnesium target and one manganese, iron, or cobalt target. Both the dynamic optical switching range and the speed of the transition depend on the magnesium-transition metal ratio. Infrared spectra of films in the transparent, hydrided (deuterided) states support the presence of the intermetallic hydride phases $\mathrm{Mg}_{3} \mathrm{MnH}_{7}, \mathrm{Mg}_{2} \mathrm{FeH}_{6}$, and $\mathrm{Mg}_{2} \mathrm{CoH}_{5}$.

Following the discovery of the switchable mirror phenomenon in yttrium and lanthanum hydrides by Huiberts et al., ${ }^{1}$ similar behavior was reported in rare earth-magnesium alloy films. ${ }^{2}$ Recently, metaltransparent hydride switching was also found in nickel-magnesium thin films. ${ }^{3}$ In all of these systems, a thin Pd overlayer (generally $>5 \mathrm{~nm}$ ) is applied to catalyze absorption and desorption of hydrogen and to protect the readily oxidized rare earth and/or $\mathrm{Mg}$ from oxidation. Infrared internal reflectance spectroscopy was used to characterize the transparent $\mathrm{Ni}-\mathrm{Mg}$ hydride films as a mixture of $\mathrm{Mg}_{2} \mathrm{NiH}_{4}$ and $\mathrm{MgH}_{2}{ }^{3}$ Other ternary hydrides containing magnesium and a first row transition metal include $\mathrm{Mg}_{2} \mathrm{CoH}_{5},{ }^{4} \mathrm{Mg}_{6} \mathrm{Co}_{2} \mathrm{H}_{11},{ }^{5} \mathrm{Mg}_{2} \mathrm{FeH}_{6},{ }^{6}$ and $\mathrm{Mg}_{3} \mathrm{MnH}_{7}{ }^{7} \mathrm{Mg}_{2} \mathrm{CoH}_{5}$ and $\mathrm{Mg}_{2} \mathrm{FeH}_{6}$ have structures similar to that of the high-temperature, cubic form of $\mathrm{Mg}_{2} \mathrm{NiH}_{4}$, with a $\mathrm{CaF}_{2}$-type metal atom arrangement. Cubic $\mathrm{Mg}_{2} \mathrm{FeH}_{6}$ contains octahedral $\mathrm{FeH}_{6}{ }^{4-}$ units, while in tetragonal $\mathrm{Mg}_{2} \mathrm{CoH}_{5}$, square-pyramidal $\mathrm{CoH}_{5}{ }^{4-}$ is present. This structural unit also appears in $\mathrm{Mg}_{6} \mathrm{Co}_{2} \mathrm{H}_{11}$, along with saddle-like $\mathrm{CoH}_{4}{ }^{5-}$ complexes. $\mathrm{Mg}_{3} \mathrm{MnH}_{7}$ contains nearly octahedral $\mathrm{MnH}_{6}{ }^{5-}$ units bridged by $\mathrm{Mg}$ in trigonal prismatic coordination, along with an isolated hydride ion bonded only to $\mathrm{Mg}$. Band structure calculations for $\mathrm{Mg}_{2} \mathrm{CoH}_{5}\left(\mathrm{E}_{\mathrm{g}}=1.92 \mathrm{eV}\right)^{8}$ and $\mathrm{Mg}_{2} \mathrm{FeH}_{6}\left(\mathrm{E}_{\mathrm{g}}=1.8 \mathrm{eV}\right)^{9}$ support experimental evidence ${ }^{4,6}$ for semiconductor behavior in these materials. $\mathrm{Mg}_{3} \mathrm{MnH}_{7}$ (calculated $\mathrm{Eg}=2.56 \mathrm{eV}$ ) ${ }^{10}$ is orange in color, ${ }^{7}$ and is also presumably semiconducting. The enthalpies of formation of $\mathrm{Mg}_{2} \mathrm{CoH}_{5}$ and $\mathrm{Mg}_{2} \mathrm{FeH}_{6}$ are 86 and $98 \mathrm{~kJ} / \mathrm{mol}$ of $\mathrm{H}_{2}$, respectively. ${ }^{4}$ Dissociation pressures at $25^{\circ} \mathrm{C}$ are estimated to be $5 \times 10^{-9}$ atm for $\mathrm{Mg}_{2} \mathrm{CoH}_{5}, 4 \times 10^{-11}$ atm for $\mathrm{Mg}_{2} \mathrm{FeH}_{6}$, and 1 x $10^{-6}$ atm for $\mathrm{MgH}_{2}$. No thermodynamic data are available for $\mathrm{Mg}_{3} \mathrm{MnH}_{7}$.
\end{abstract}

Mixed metal thin films of $\mathrm{Co}, \mathrm{Fe}$, and $\mathrm{Mn}$ with $\mathrm{Mg}$ were deposited by DC magnetron co-sputtering from separate 2 in diameter transition metal and $\mathrm{Mg}(99.98 \%)$ targets onto glass substrates with or without transparent conductive coatings. The base pressure was $1.4 \times 10^{-7} \mathrm{Torr}$, process pressure 2 mTorr (Ar), target-to-substrate distance $7.5 \mathrm{~cm}$, power levels for $\mathrm{Mn}-\mathrm{Mg}$ deposition: $\mathrm{Mn} 15 \mathrm{~W}, \mathrm{Mg}$ $40 \mathrm{~W}$; for Fe-Mg: Fe 28 W, Mg 36 W; for Co-Mg: Co 29 W, Mg 35 W. The Pd over-layer was applied at 10 mTorr Ar pressure, Pd power 12 watts. Film thicknesses were measured by stylus

*tjrichardson@lbl.gov 
profilometry. Samples for mid-IR internal reflectance-absorbance spectroscopy were deposited on 25 $\mathrm{mm}$ diameter $\mathrm{ZnSe}$ discs. The spectra were obtained by reflectance from the Pd cap layer at $45^{\circ}$ through the $\mathrm{ZnSe}$ substrates.

Switching from the as-deposited mirror state to the transparent state was achieved by exposing the films to a dry gas stream containing $4 \%$ hydrogen in argon or helium. The mirror state was recovered by exposing the films to ambient air. Electrochemical switching was carried out in aqueous alkaline electrolyte (1-5 M KOH, Pt counter electrode, $\mathrm{HgO} / \mathrm{Hg}$ reference), with in situ measurement of optical transmission spectra or photopic transmittance. Film compositions were determined by Rutherford backscattering spectrometry (RBS) and particle induced x-ray emission (PIXE).

The freshly deposited films were amorphous by X-ray diffraction (XRD) in every case, showing only weak reflections due to $\mathrm{Pd}$. No changes were observed in the XRD patterns of films maintained in a $4 \% \mathrm{H}_{2}$ atmosphere. The films were highly reflecting in the metallic state (Fig. 1) and had very low transmittance (Fig.2). The sharp drop in reflectance around $350 \mathrm{~nm}$ is due to absorption by the substrate. In the transparent states, there is some contribution to the reflectance from the Pd layer, which remains metallic but is somewhat more transparent when loaded with hydrogen. ${ }^{11} \mathrm{Co}-\mathrm{Mg}$ hydride films were strongly absorbing below $500 \mathrm{~nm}$, due in part to their higher reflectance in this region. The maximum transmittance depended upon the thicknesses of both the mixed metal film and the Pd overlayer, as well as on the atomic ratio of transition metal (T) to $\mathrm{Mg}$. Cosputtering from offset sources produced films with position-dependent $\mathrm{T}: \mathrm{Mg}$ atomic ratios ranging from about 1:1 to 1:10. Regions with ratios greater than about 1:2 did not switch completely and remained reflecting in appearance. For Fe:Mg between 1:2 and 1:7, switching was rapid; the maximum transparency was found at around 1:5. For Mn:Mg the maximum transparency was observed at ca. 1:6. For all three mixtures, areas with T:Mg ratios lower than about 1:12 did not switch at all.

Gasochromic switching from the metallic to the transparent state generally was complete in less than $10 \mathrm{~s}$. The reverse transition in air required 30 to $120 \mathrm{~s}$. Electrochromic switching was somewhat slower. The electrochemical hydrogen loading behavior of these mixed metal films was similar to that of Ni-Mg films. ${ }^{3}$ The return to the mirror state, however, was somewhat slower and in some Fe-Mg and $\mathrm{Mn}-\mathrm{Mg}$ samples appeared to proceed in two steps. This may be due to the greater thermodynamic stability of the more hydrogen-rich ternary compounds relative to $\mathrm{MgH}_{2}\left(74 \mathrm{~kJ} / \mathrm{mol} \mathrm{H}_{2}\right){ }^{12}$ Switching speeds deteriorated gradually with cycling (thirty or more cycles were observed), but were found to be stabilized by the use of dry, $\mathrm{CO}_{2}$-free air for hydrogen removal.

Internal reflectance-absorbance infrared spectra for the three hydride mixtures are shown in Figure 3. In each case, a composition gradient existed from one side of the sample to the other. Spectra taken from regions with different transition metal-to-magnesium ratios were identical except that the intensities of all observed absorption bands varied directly with the absolute quantity of the transition metal present. No contribution to the spectra from free $\mathrm{MgH}_{2}$ was evident. $\mathrm{MgH}_{2}$, having the rutile structure, does not contain isolated structural units, and therefore has only no identifiable absorption bands within the accessible spectral range. The similarity between the spectra of the Fe- $\mathrm{Mg}$ and $\mathrm{Mn}$ $\mathrm{Mg}$ hydrides is due to the fact that both ternary hydrides contain an octahedral $\mathrm{MH}_{6}$ unit. The higher frequencies of the $\mathrm{FeH}_{6}{ }^{4-}$ vibrations relative to those for $\mathrm{MnH}_{6}{ }^{5-}$ are consistent with the higher positive charge on Fe (+2) vs. Mn (+1), and shorter Fe-H bond length (1.49 $\AA$ vs. $1.63 \AA$ ). In all cases, the frequency ratios between corresponding peaks in the hydride and deuteride spectra range from 1.25 to 1.37. These vibrations involve primarily motion of the hydrogen (deuterium) atoms, hence the reduced 
mass for each mode is approximately that of the light atoms. The spectrum of $\mathrm{Mg}_{2} \mathrm{CoH}_{5}$ is somewhat more complicated due to the lower symmetry of the square pyramidal $\mathrm{CoH}_{5}{ }^{4-}$. The vibrational frequencies, like the Co-H bond lengths of $1.51 \AA$ (equatorial) and $1.59 \AA$ (axial) are intermediate between those of $\mathrm{Mg}_{2} \mathrm{FeH}_{6}$ and $\mathrm{Mg}_{3} \mathrm{MnH}_{7}$.

The switching mechanism in the three systems studied appears, as in the case of $\mathrm{Ni}-\mathrm{Mg}$ films, to be reversible formation of a mixture of $\mathrm{MgH}_{2}$ and the previously known ternary hydrides. The dramatic changes in both transmittance and reflectance in these materials may lead to useful applications in architectural heat and light control as well as in optoelectronics.

\section{Acknowledgement}

This work was supported by the Assistant Secretary for Energy Efficiency and Renewable Energy, Office of Building Technology, State and Community Programs, Office of Building Research and Standards of the US Department of Energy under Contract No. DE-AC03-76SF00098.

\section{References}

1. J.N. Huiberts, R. Griessen, J.H. Rector, R.J. Wijngaarden, J.P. Dekker, D.G. de Groot, and N.J. Koeman, Nature (London) 380, 231 (1996).

2. P. van der Sluis, M. Ouwerkerk, and P.A. Duine, Appl. Phys. Lett. 70, 3356 (1997).

3. T. J. Richardson, J. L. Slack, R. D. Armitage, R. Kostecki, B. Farangis, and M. D. Rubin, Appl. Phys. Lett. 78, 3047 (2001).

4. P. Zolliker, K. Yvon, P. Fischer, and J. Schefer, Inorg. Chem. 24, 4177 (1985).

5. R. Cerny, F. Bonhomme, K. Yvon, P. Fischer, P. Zolliker, D. E. Cox, and A Hewat, J. Alloys Compd. 187, 233 (1992).

6. J. J. Didisheim, P. Zolliker, K. Yvon, P. Fischer, J. Schefer, and M. Gubelmann, Inorg. Chem. 23, 1953 (1984).

7. M. Bortz, B. Bertheville, K. Yvon, E. A. Movlaev, V. N. Verbetsky, and F. Fauth, J. Alloys Compd. 279, L8 (1998).

8. E. Belin, M. Gupta, P. Zolliker, and K. Yvon, J. Less-Common Met. 130, 267 (1987).

9. M. Gupta, J. Less-Common Met. 103, 325 (1984).

10. M. Gupta, private communication.

11. K. von Rottkay, M. Rubin, and P.A. Duine, J. Appl. Phys. 85, 408 (1999).

12. B. Bogdanović, Int. J. Hydrogen Energy 9, 937 (1984). 

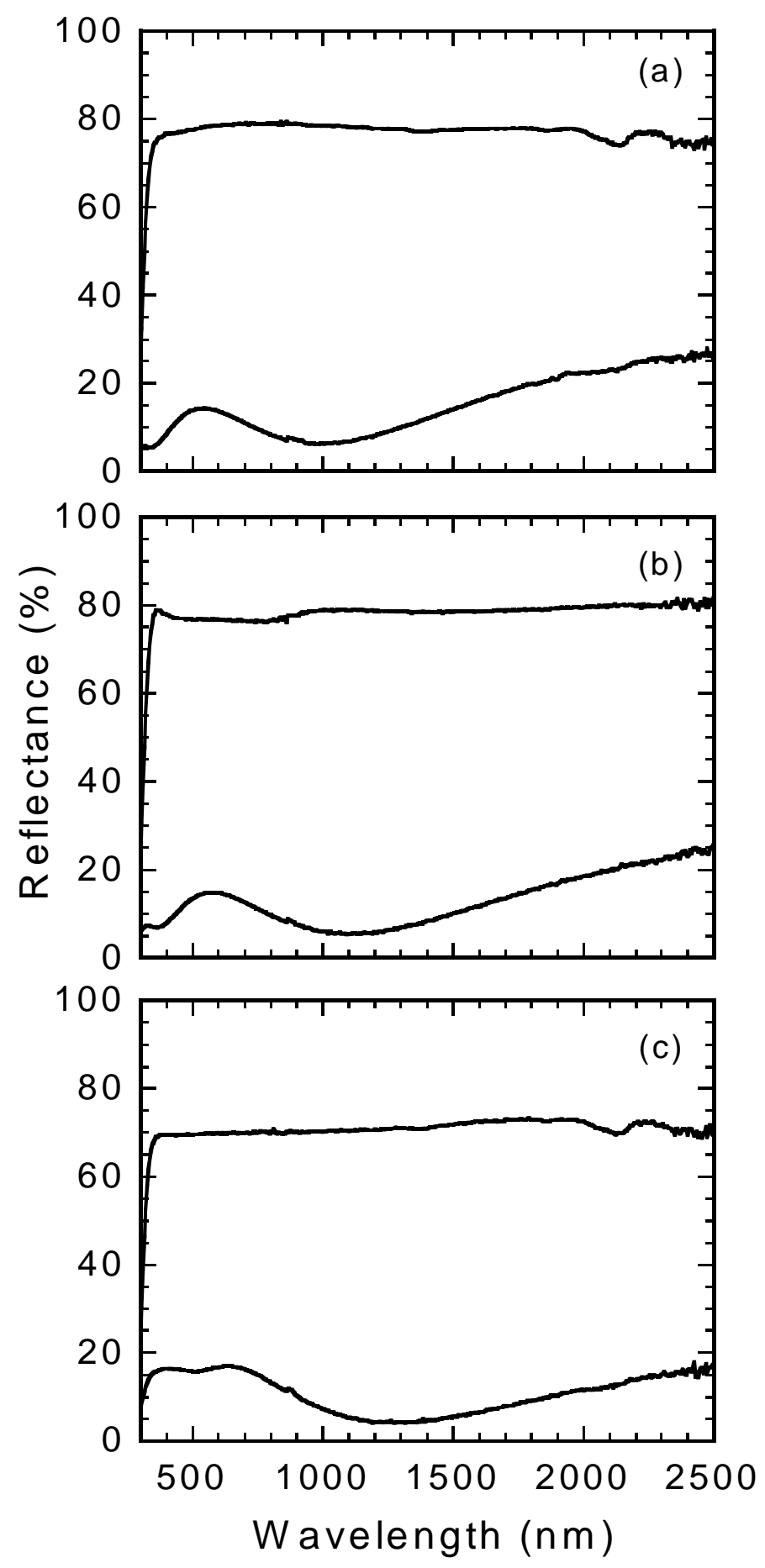

Figure 1. Vis-NIR reflectance spectra of (a) $60 \mathrm{~nm} \mathrm{Mn-Mg,} \mathrm{(b)} 40 \mathrm{~nm} \mathrm{Fe}$ $\mathrm{Mg}$, (c) $40 \mathrm{~nm}$ Co-Mg films (T:Mg ca. 1:6) with $7 \mathrm{~nm}$ Pd overlayers on glass substrates in the metallic (upper curve) and hydride (lower curve) states. Spectra were recorded from the substrate side. 


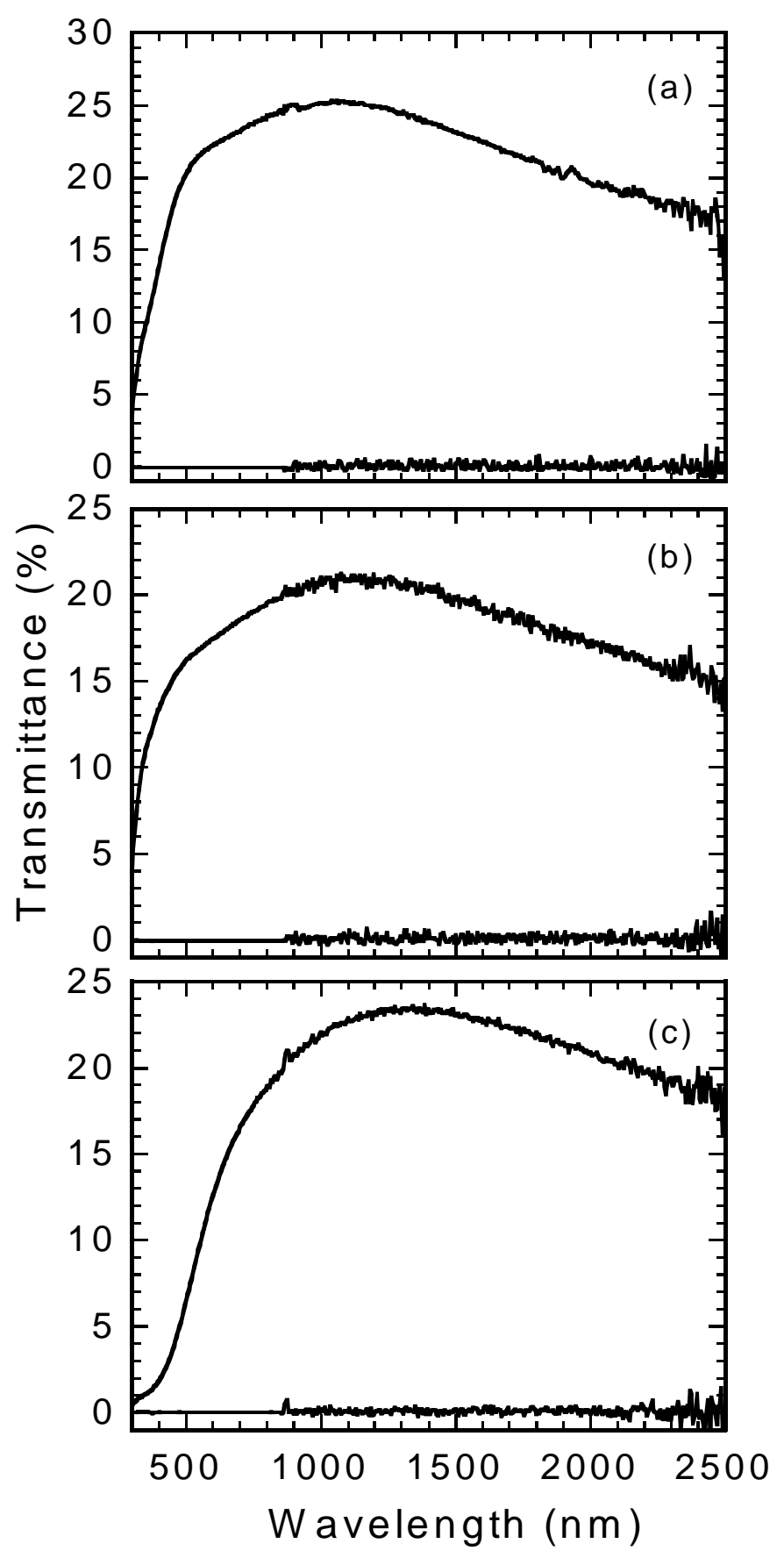

Figure 2. Vis-NIR transmittance spectra of (a) $60 \mathrm{~nm} \mathrm{Mn}-\mathrm{Mg}$, (b) $40 \mathrm{~nm}$ Fe-Mg, (c) $40 \mathrm{~nm}$ Co-Mg films (T:Mg ca. 1:6) with $7 \mathrm{~nm}$ Pd overlayers on glass substrates in metallic (lower curve) and hydride (upper curve) states. 


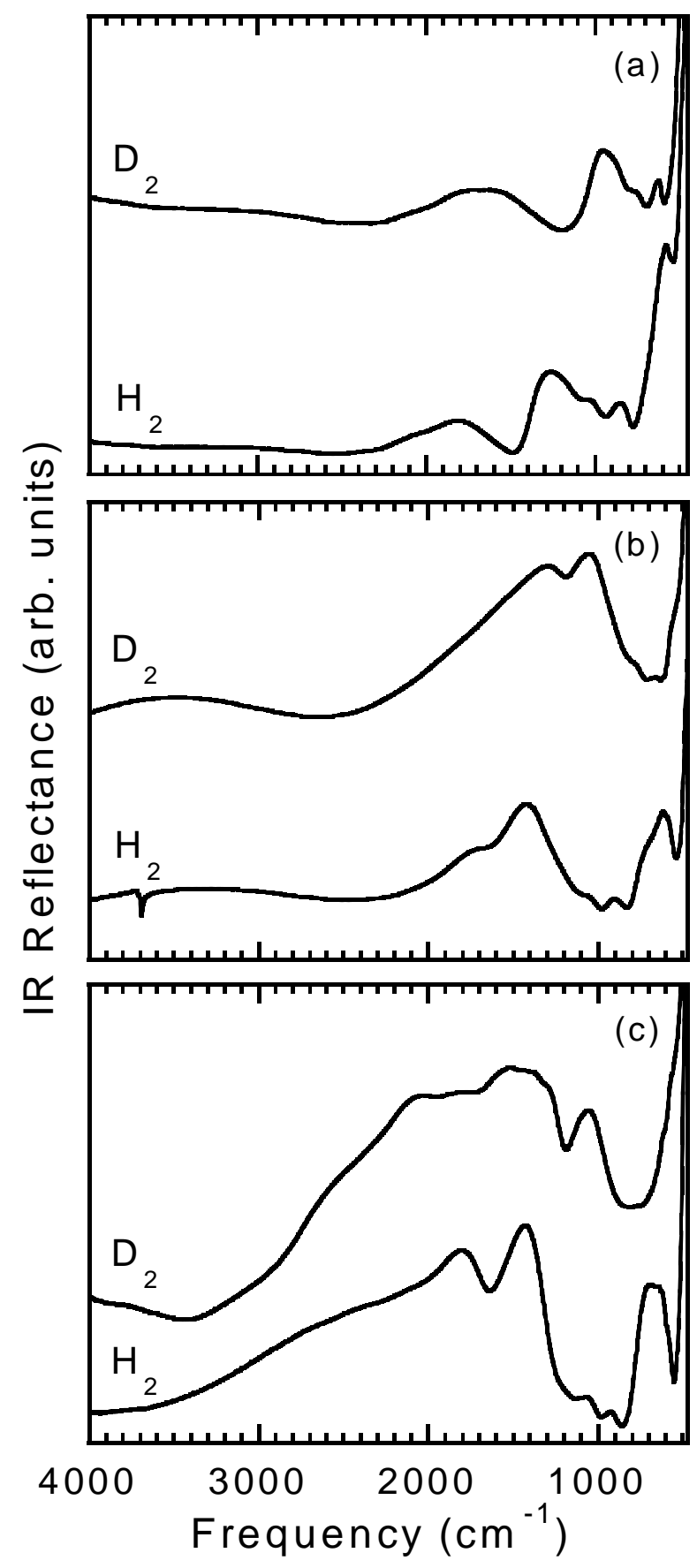

Figure 3. Internal reflectance infrared spectra of (a) $400 \mathrm{~nm} \mathrm{Mn-Mg}$, (b) $385 \mathrm{~nm} \mathrm{Fe}-\mathrm{Mg}$, (c) $250 \mathrm{~nm}$ Co-Mg films on $\mathrm{ZnSe}$ substrates following loading in $\mathrm{H}_{2}$ and $\mathrm{D}_{2}$. 